\title{
Nível crítico de boro em cenoura cultivada em um solo sob cerrado
}

\author{
Manoel Vicente de Mesquita Filho; Antonio Francisco Souza; Henoque R. da Silva \\ Embrapa Hortaliças, C. Postal 218, 70359-970 Brasília-DF; E-mail: mesquita@cnph.embrapa.br
}

\begin{abstract}
RESUMO
Realizou-se em campo um experimento em um Latossolo Vermelho, distrófico argiloso, sob regime isohipertérmico, para avaliar a resposta da cenoura (Daucus carota) $\mathrm{cv}$. Alvorada à adubação com boro. O delineamento experimental consistiu de blocos casualizados com seis tratamentos $\left(0 ; 1,7 ; 3,4 ; 5,1 ; 6,8\right.$ e $\left.10,2 \mathrm{~kg} \mathrm{~B} \mathrm{ha}^{-1}\right)$ com quatro repetições. $\mathrm{O}$ extrator utilizado para a determinação de boro no solo e na matéria seca das folhas foi a Azometina-H. A produção máxima de raízes comercializáveis de cenoura foi de $50,6 \mathrm{t} \mathrm{ha}^{-1}$, obtida com o teor estimado de $0,55 \mathrm{mg} \mathrm{kg}^{-1}$ de boro no solo. O nível crítico de boro no solo, associado a $90 \%$ da produção máxima comercializável estimada de cenoura foi de $0,45 \mathrm{mg} \mathrm{kg}^{-1}$. Numa primeira aproximação, os níveis de $\mathrm{B}\left(\mathrm{mg} \mathrm{kg}^{-1}\right)$ no solo foram assim classificados: baixo $(\leq 0,30)$; médio $(0,31-0,44)$, adequado $(0,45-0,55)$ e alto $\left(\geq 0,55 \mathrm{mg} \mathrm{kg}^{-1} \mathrm{~B}\right)$, e para efeito de diagnose foliar com base nos teores na matéria seca das folhas em: baixo $(\leq 24,1)$, médio $(25-$ $34,9)$, adequado $(35-51,9)$ e alto $\left(\geq 51,9 \mathrm{mg} \mathrm{B} \mathrm{kg}^{-1}\right)$.
\end{abstract}

Palavras-chave: Daucus carota, oxisolo, micronutriente.

\begin{abstract}
Critical level of boron on carrot cultivated in a cerrado soil

A field experiment was carried out on a clayey Dystrophic Red Latosol (Oxisol), under isohyperthermic regime to evaluate the effect of boron application on carrot root yield (Daucus carota) cv. Alvorada. A factorial scheme layout with six treatments $(0 ; 1.7 ; 3.4$; 5.1; 6.8; and $\left.10.2 \mathrm{~kg} \mathrm{~B} \mathrm{ha}^{-1}\right)$ was arranged in a randomized complete block design with three replications. Azomethine-H was used as extractant for boron determination in soil and plant material. The maximum marketable root yield was $50.6 \mathrm{t} \mathrm{ha}^{-1}$, obtained under the estimated concentration of $0.55 \mathrm{mg} \mathrm{B} \mathrm{kg}^{-1}$ in the soil. The critical boron (B) concentration in the soil associated with $90 \%$ of the maximum marketable root yield was $0.45 \mathrm{mg} \mathrm{kg}^{-1}$. As a first approximate, the levels of B in the soil could be classified as low $(\leq 0.30)$, medium $(0.31-0.44)$, adequate $(0.45-0.55)$ and high $(\geq 0.55$

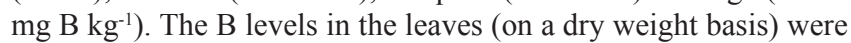
classified accordingly to the following ranges: low $(\leq 24.1)$, medium (25-34,9), adequate (35-51.9) and high ( $\left.\geq 51.9 \mathrm{mg} \mathrm{kg}^{-1} \mathrm{~B}\right)$.
\end{abstract}

Keywords: Daucus carota, oxisol, micronutrient.

(Recebido para publicação em 20 de janeiro de 2004 e aceito em 17 de novembro de 2004)

$\mathrm{N}^{\circ}$ o Brasil, o cultivo da cenoura abrange cerca de 28.000 hectares ano $^{-1}$, perfazendo um volume de produção anual de 800.000 t de raízes comercializáveis. Em 2001, o valor total dessa produção foi de 143 milhões de dólares, equivalente a $5 \%$ do valor total da produção comercializável de hortaliças (Fontes e Vilela, 2002). No país, destaca-se a região de São Gotardo (MG), com produção comercializável média de 48 t em uma área de 8.000 ha.

No Distrito Federal, as produções médias comercializáveis de cenoura entre os horticultores em 1985, 1997 e 2001 foram 40, 24 e 24,9 $\mathrm{t} \mathrm{ha}^{-1}$, correspondentes às áreas de 1000, 1312 e 1500 ha, respectivamente. De acordo com a EMATER-DF* ${ }^{*}$ esse decréscimo de produtividade pode ser atribuído ao manejo inadequado da cultura por ocasião do raleamento, induzindo uma acentuada diminuição e desuniformidade no stand, e/ou à não realização de análises quími- cas para avaliar a fertilidade do solo pela maioria dos horticultores. Sem os resultados da análise de solo os produtores de hortaliças utilizam um manejo inadequado do solo (Mesquita Filho, 1996), contribuindo assim para o decréscimo nos teores de matéria orgânica e, conseqüentemente, na disponibilidade de micronutrientes, em especial o boro por encontrar-se a ela associado (Fageria, 1996). Dessa maneira, a deficiência desse nutriente agiria como fator limitante à produção.

Nas condições edafoclimáticas do Centro Sul do Brasil, o boro é o micronutriente mais importante para a maioria das hortaliças (Filgueira, 2000). Shorrocks citado por Trani et al. (1993), menciona a cenoura dentre as hortaliças mais sensíveis à deficiência de boro. Mesquita Filho e Souza (1986), observaram que a aplicação a lanço de $2,2 \mathrm{~kg}$ $\mathrm{B} \mathrm{ha}^{-1}$, na forma de bórax a um Latossolo Vermelho distrófico argiloso, sob cer- rado do Distrito Federal, contendo 0,48 mg B kg-1, diminuiu os sintomas de deficiência desse nutriente na cultura da cenoura cv. Brasília.

Devido à falta de informação científica, as adubações de recomendação com boro para o cultivo de hortaliças não somente no Distrito Federal, mas em todo Brasil, são resultantes de observações de horticultores e de extensionistas. Para o cultivo de hortaliças em solos sob cerrado aplicam-se a lanço 10 a $20 \mathrm{~kg}$ de bórax ha-1.

A Embrapa Hortaliças incorporou algumas características à cenoura cv. Brasília, resultando em 2000 na cv. Alvorada (Vieira et al., 2000), a qual possui conteúdo de carotenóides totais $35 \%$ superior em relação às demais cultivares comerciais em uso no Brasil e alta resistência aos nematóides formadores de galhas nas raízes. A quantidade de sementes da cv. Alvorada produzidas pelas companhias e disponibilizadas

\footnotetext{
* Informação fornecida ao primeiro autor por Romério José de Andrade, engenheiro agrônomo, articulador de Pesquisa e Extensão/EMATER-DF; E-mail: romerio@enph.embrapa.br
} 
para venda no Brasil ${ }^{* *}$ é suficiente para o plantio de 7 a $10 \%$ da área utilizada com cenoura no país.

Face ao exposto, o presente trabalho teve a finalidade de obter informações relativas a produção comercializável de cenoura cv. Alvorada, mediante aplicação à lanço de boro em um solo representativo de cerrado do Distrito Federal em condições de regime isohipertérmico.

\section{MATERIAL E MÉTODOS}

O experimento foi realizado em um Latossolo Vermelho distrófico de textura argilosa, localizado na área experimental da Embrapa Hortaliças, em Brasília. O solo (média de 20 subamostras feitas em 25/09/2000) na camada 0-20 cm de profundidade, antes do início do experimento, possuía as seguintes características: $\mathrm{pH}$ em $\mathrm{H}_{2} \mathrm{O}$ $(1: 2,5)=5,20 ; \mathrm{P}=17,6 \mathrm{mg} \mathrm{kg}^{-1} ; \mathrm{K}=$ $181,3 \mathrm{mg} \mathrm{kg}^{-1} ; \mathrm{Al}^{3+}=3,9 \mathrm{mmol} \mathrm{kg}^{-1} ; \mathrm{H}^{+}$ $+\mathrm{Al}^{3+}=7,40 \mathrm{mmol} \mathrm{kg}^{-1} ; \mathrm{Ca}^{+2}=20,4$ mmol $\mathrm{kg}^{-1} ; \mathrm{Mg}^{+2}=8,7$ mmol $\mathrm{kg}^{-1}$; matéria orgânica $=32,3 \mathrm{~g} \mathrm{~kg}^{-1} \mathrm{e} \mathrm{B}=0,24$ $\mathrm{mg} \mathrm{kg}^{-1}$. A análise textural revelou teores de argila $=516 \mathrm{~g} \mathrm{~kg}^{-1}$; silte $=380 \mathrm{~g}$ $\mathrm{kg}^{-1}$; areia fina $=66 \mathrm{~g} \mathrm{~kg}^{-1} \mathrm{e}$ areia grossa $=38 \mathrm{~g} \mathrm{~kg}^{-1}$. Os teores de caulinita e goetita foram 310 e $25 \mathrm{~g} \mathrm{~kg}^{-1}$, respectivamente. De acordo com a Taxonomia de Solos (USDA, 1975), o regime de temperatura do solo é isohipertérmico.

Em 03/11/2000 efetuou-se a calagem com calcário dolomítico PRNT $=100 \%$ (relação Ca:Mg = 4:1), na razão de 1,23 $\mathrm{t} \mathrm{ha}^{-1}$, segundo o critério de saturação por bases, visando uma elevação a $85 \%$. Metade da dose foi distribuída antes da aração, a dose restante foi após, incorporada por grade leve. Após 58 dias, aplicou-se de uma só vez uma adubação uniforme, correspondente a $210 \mathrm{~kg}$ de $\mathrm{P}_{2} \mathrm{O}_{5}$ ha $^{-1}$ e $80 \mathrm{~kg}$ de $\mathrm{K}_{2} \mathrm{O}$ $\mathrm{ha}^{-1}$ nas formas de superfosfato triplo $\left(45 \%\right.$ de $\left.\mathrm{P}_{2} \mathrm{O}_{5}\right)$ e cloreto de potássio $\left(58 \% \mathrm{~K}_{2} \mathrm{O}\right)$. Aplicou-se $120 \mathrm{~kg}$ de $\mathrm{N}$ ha ${ }^{1}$, sob a forma de uréia, parcelado $1 / 3$ no plantio e o restante aos 60 dias. Aplicaram-se ainda $10,9 \mathrm{~kg} \mathrm{ha}^{-1}$ de $\mathrm{Mg}, 4,8$ $\mathrm{kg} \mathrm{ha}^{-1} \mathrm{de} \mathrm{Cu}, 6,3 \mathrm{~kg} \mathrm{ha}^{-1}$ de $\mathrm{Zn} \mathrm{e} 0,195$ $\mathrm{kg} \mathrm{ha}^{-1}$ de Mo, nas formas de sulfato de magnésio, sulfato de cobre, sulfato de zinco e molibdato de amônio, respectivamente, incorporados mecanicamente ao solo até a profundidade de $20 \mathrm{~cm}$.

Foram utilizados seis tratamentos distribuídos em blocos casualizados com quatro repetições. Cada parcela experimental constituiu-se de quatro canteiros, medindo cada um $4 \mathrm{~m}$ de comprimento por $1 \mathrm{~m}$ de largura e 0,15 $\mathrm{m}$ de altura, contendo 4 fileiras de plantas por canteiro, no espaçamento de 0,25 $\mathrm{m}$ entre fileiras por $0,05 \mathrm{~m}$ entre plantas na fileira, resultando numa parcela com área total de $16 \mathrm{~m}^{2} \mathrm{e}$ área útil de 7,2 $\mathrm{m}^{2}$.

Os tratamentos avaliados foram: 0 ; 1,$7 ; 3,4 ; 5,1 ; 6,8$ e $10,2 \mathrm{~kg} \mathrm{~B} \mathrm{ha}^{-1}$ na forma de bórax (11,3\% de B), distribuídos a lanço sobre a superfície de cada parcela e incorporados mecanicamente à profundidade de $20 \mathrm{~cm}$. Em 03/01/01 semeou-se a cenoura cv. Alvorada, sob regime de irrigação por aspersão. A colheita foi realizada em 23/04/01. Considerou-se raízes comercializáveis aquelas com diâmetro e comprimento médios de 2,5 a $4 \mathrm{~cm}$ e de 10 a $20 \mathrm{~cm}$, respectivamente, livres de nematóides, rachaduras e bifurcações, para representar a produtividade da cultura. Tomaram-se em triplicata por tratamento, 20 plantas ao acaso dentro de cada parcela útil e fez-se a separação em parte aérea (folhas) e raízes comercializáveis para a determinação em laboratório de pesos fresco e seco, as quais foram lavadas em água deionizada, seguido de secagem e pesagem em estufa com circulação de ar forçada com temperatura próxima de $65^{\circ} \mathrm{C}$ até peso constante. Os teores de boro no solo e na matéria seca das folhas foram determinados conforme Mesquita Filho et al. (1996).

Para a determinação dos níveis críticos de boro tanto no solo e na matéria seca das folhas, adotou-se o critério utilizado por Carvalho e Oliveira (1983), Alvares et al. (1985) e Mesquita Filho et al. (1996), que consiste em correlacionar $90 \%$ da produção máxima da cultura com a quantidade do nutriente no solo ou na planta, considerando-se que os demais nutrientes estavam em níveis adequados.

\section{RESULTADOS E DISCUSSÃO}

Na Figura 1 observa-se que a produção máxima de raízes comercializáveis de cenoura estimada pela derivada primeira da função quadrática de produção correspondente a $50,6 \mathrm{t} \mathrm{ha}^{-1}$, foi obtida com o teor de boro no solo de $0,55 \mathrm{mg} \mathrm{B} \mathrm{kg}^{-1}$. Entretanto, 48,4 t ha-1 $(90 \%)$ desta produção foi obtida com o teor estimado de 0,45 $\mathrm{kg} \mathrm{B} \mathrm{kg}^{-1}$, enquanto os teores de 0,37 mg B kg-1 (correspondente a $20 \mathrm{~kg}$ de bórax ha ${ }^{-1}$ normalmente usada no Distrito Federal) e $0,30 \mathrm{mg} \mathrm{B} \mathrm{kg}^{-1}$ proporcionaram $43,5 \mathrm{t} \mathrm{ha}^{-1}(82 \%)$ e $36,4 \mathrm{t} \mathrm{ha}^{-1}$ (70\%) respectivamente.

$\mathrm{Na}$ Figura 2, observa-se que os percentuais acima mencionados corresponderam a 51,9; 34,9; 29,9 e 24,1 $\mathrm{mg}$ de $\mathrm{B} \mathrm{kg}^{-1}$ na matéria seca de folhas de cenoura. Maroto Borrego (1983) afirma que em solos ácidos, teores de boro compreendidos entre 0,3 e $0,4 \mathrm{mg} \mathrm{kg}^{-1}$ são considerados adequados para o cultivo da cenoura. Shorrocs citado por Trani et al. (1993), classifica os teores desse nutriente na matéria seca dessa hortaliça em: deficiente quando $<14$, normal 32-200 e alto $>200 \mathrm{mg} \mathrm{B} \mathrm{kg}{ }^{-1}$. Stoyanov (1985), também citado por Trani et al. (1993), relata que em folhas jovens de cenoura, o nível crítico é de $16 \mathrm{mg} \mathrm{B} \mathrm{kg}^{-1}$.

Em um trabalho preliminar realizado entre março e julho de 1986, observou-se deficiência de boro na cultura da cenoura cv. Brasília, cultivada em um LV distrófico argiloso (Mesquita Filho e Souza, 1986), de mineralogia goetítica, em condições de regime isohipertérmico, sob cerrado do Distrito Federal, que continha originalmente $\mathrm{pH}$ $(1: 2,5)$ em água $=5,4$, matéria orgânica $=2,81 \mathrm{~g} \mathrm{~kg}^{-1}$ e $\mathrm{B}=0,48 \mathrm{mg} \mathrm{kg}^{-1}$.

\footnotetext{
**Informação verbal prestada pelo Dr. Luciano Werner (ISLA) ao Dr. Jairo Vidal Vieira, pesquisador da Embrapa Hortaliças.
} 


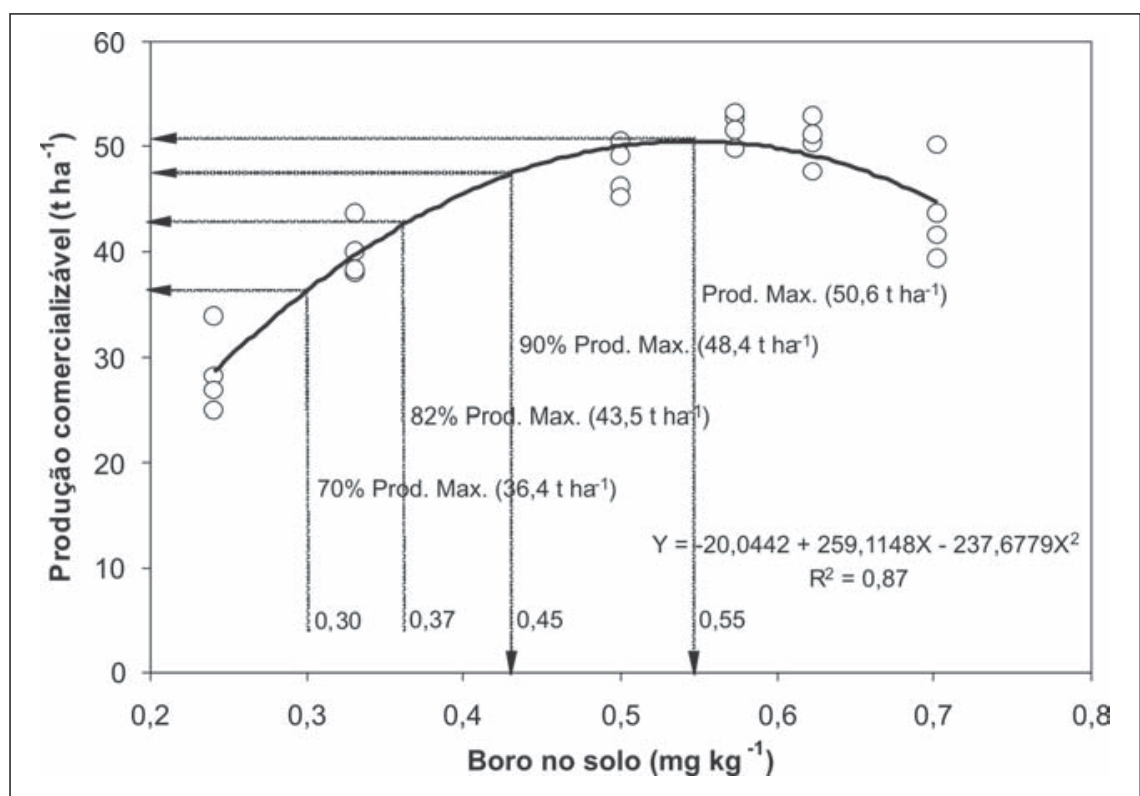

Figura 1. Produção de raízes comercializáveis de cenoura cv. Alvorada, em função de doses de boro aplicadas a um Latossolo Vermelho (LV) distrófico, de textura argilosa, sob cerrado, em condições de regime isohipertérmico. Brasília, Embrapa Hortaliças, 2001.

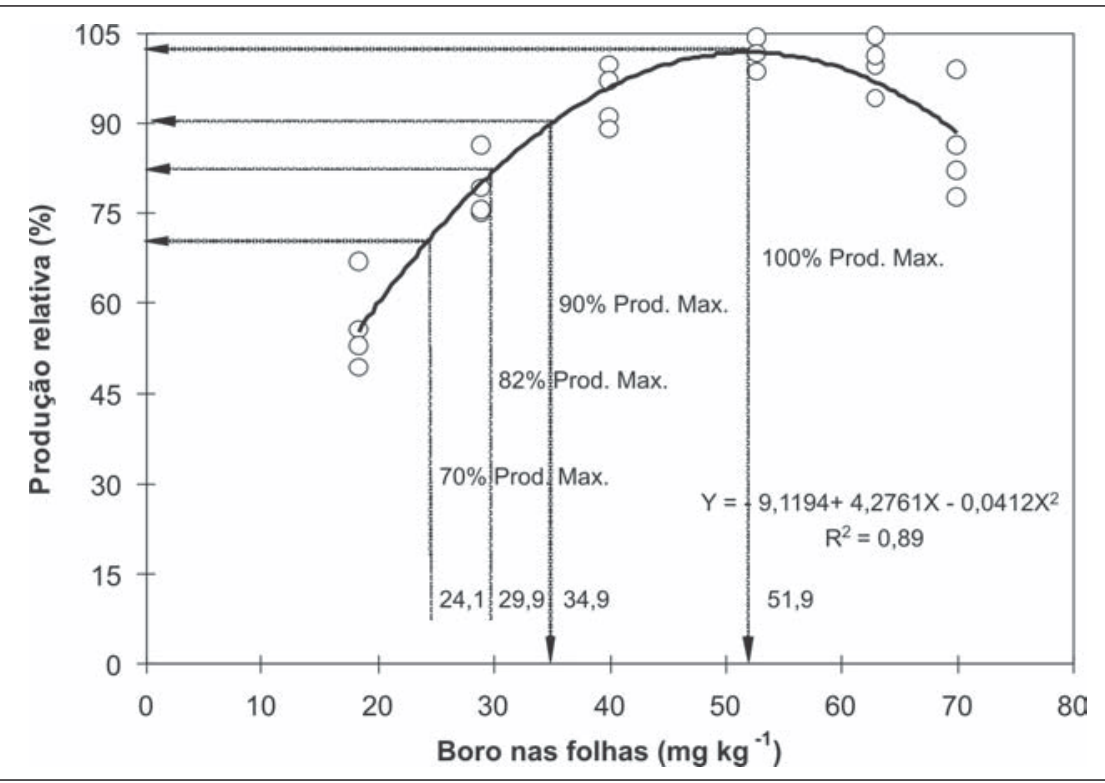

Figura 2. Produção relativa de cenoura cv. Alvorada, cultivada em um Latossolo Vermelho (LV) distrófico, de textura argilosa, sob cerrado, em condições de regime isohipertérmico, em função dos teores de boro na matéria seca foliar. Brasília, Embrapa Hortaliças, 2001.

O solo do presente trabalho também é LV distrófico argiloso, em condições de regime isohipertérmico, porém de mineralogia caulinítica e com $\mathrm{B}=0,24$ $\mathrm{mg} \mathrm{kg}^{-1}$. Assim, pode-se inferir que cultivares de uma mesma espécie podem possuir diferentes sensibilidades com relação a esse micronutriente e/ou que no solo, um ou mais fatores estejam participando ativamente do processo de fi-
(Nielson et al., 1985); d) matéria orgânica (Berger e Truog, 1945; Olson e Berger, 1946; Miljkovic et al., 1966; Elrashidi e O'Corner, 1981). Em se tratando de solos com diferentes texturas, este fator também deve ser considerado (Olson e Berger, 1946, Wear e Patterson, 1962).

Neste trabalho, as doses de boro influenciaram $(p<0.01)$ na produção comercializável de cenoura e nos teores de boro disponível no solo. Dessa maneira, considerando-se como nível crítico externo de boro aquele associado a $90 \%$ da produção máxima comercializável, a probabilidade de ocorrência de resposta da cenoura com respeito às adubações boratadas, realizadas em solos semelhantes ao do trabalho em epígrafe seria minimizada quando os teores de B-disponível (extrator Azometina-H), estivessem compreendidos entre 0,45 e $0,55 \mathrm{mg} \mathrm{B} \mathrm{kg}^{-1}$.

Vale ressaltar que neste trabalho, assim como em outros anteriores realizados com as culturas de batata (Mesquita Filho e Oliveira, 1984), repolho (Alvares et al., 1985) e mandioquinhasalsa (Carvalho e Oliveira, 1983; Mesquita Filho et al., 1996) conduzidos em diferentes tipos de solos sob cerrado, em condições de regime isohipertérmico, não foram observados efeitos fitotóxicos, corroborando a hipótese que, em condições de campo, o boro encontra-se predominantemente como $\mathrm{H}_{3} \mathrm{BO}_{3}$, não dissociado, facilmente lixiviável, como também reagindo com os compostos diólicos da matéria orgânica (Reisenauer et al., 1973). Segundo Garavito e León (1978), solos deficientes de boro possuem maior poder de fixação que aqueles menos deficientes. Portanto, em tais condições é pouco provável obter sintomas de toxicidade de boro, mesmo em níveis elevados de adubação (Mesquita Filho e Oliveira, 1984). Ademais, tanto neste quanto naqueles trabalhos, o bórax foi distribuído a lanço e incorporado ao solo o que pode ter resultado em um menor acúmulo da fonte de boro no ambiente radicular. Em nenhum dos tratamentos visualizou-se sintomas de deficiência ou fitotoxicidade de boro na planta. Entretanto pode-se observar nas Figuras $1 \mathrm{e}$ 2 que nas doses mais elevadas houve excesso desse micronutriente. 
Numa primeira aproximação, tomando-se como critério $90 \%$ da produção máxima de raízes comercializáveis, propõe-se quatro níveis de boro ( $\mathrm{mg} \mathrm{B} \mathrm{kg}^{-1}$ de solo) para solos com atributos semelhantes ao do presente trabalho: baixo $\leq 0,30$; médio de $0,31-0,44$, adequado de $0,45-0,55$ e alto $\geq 0,55$; assim como para efeito de diagnose foliar de cenoura com base no teor de boro na matéria seca da parte aérea em: baixo $\leq 24,1$, médio de 25-34,9, adequado de $35-51,9$ e alto $\geq 51,9$ de $\mathrm{mg} \mathrm{B} \mathrm{kg}^{-1}$, respectivamente.

\section{AGRADECIMENTOS}

Os autores agradecem ao pesquisador Antonio Williams Moita, pelo apoio estatístico, ao técnico agrícola João Lopes da Cruz e sua equipe, de campo.

\section{LITERATURA CITADA}

ALVARES, M.C.; OLIVEIRA, S.A.; MATTOS, J.K.A.; MESQUITA FILHO, M.V.. Resposta do repolho à adubação com bórax. Horticultura Brasileira, Brasília, v.3, n.2, p.18-21, 1985.

BARTLETT, R.J.; PICARELLI, C.J. Availability of boron and phosphorus as affected by liming an acid potato soil. Soil Science, v.116, n.2, p.77-83, 1973.

BERGER, K.C.; TRUOG, E. Boron availability in relation to soil reaction and organic matter content. Soil Science of America Proceedings, v.10, p.871-876, 1945.

BUZETTI, S.; MURAOKA, T.; SÁ, M.E. Doses de boro em soja, em diferentes condições de acidez do solo: I. Produção de matéria seca e de grãos e nível crítico no solo. Revista Brasileira de Ciência do Solo, Campinas, v.14, n.2, p.157-161, 1990a.
BUZETTI, S.; MURAOKA, T.; SÁ, M.E. Doses de boro na soja, em diferentes condições de acidez do solo: II Níveis críticos na planta do solo. Revista Brasileira de Ciência do Solo, Campinas, v.14, n.2, p.163-166, 1990b.

CARVALHO, M.C.G.S.; OLIVEIRA, S.A. Adubação da batata-salsa (Arracacia esculenta) com bórax. In: CONGRESSO BRASILEIRO DE OLERICULTURA, 23, 1983, Rio de Janeiro. Resumos... Rio de Janeiro: SOB, 1983. p. 6.

ELRASHIDI, M.A.; O'CONNER, G.A. Boron sorption and desorption in soils. Soil Science Society of America Journal, v.46, p.27-31, 1981. FAGERIA, N.K. Maximizing crop yields. New York: Marcel Deckker, 1996. 274 p.

FILGUEIRA, F.A.R. Novo manual de olericultura: agrotecnologia moderna na produção e comercialização de hortaliças. Viçosa: UFV, 2000. 402 p.

FONTES, R.R; VILELA, N.J. The current status of the Brazilian vegetable crops and future opportunities. Acta Horticulturae, n.607, p.135141, 2003.

GARAVITO, F.; LEÓN, A. Propriedades del suelo en relación con deficiencias de boro en el Valle de Cauca. Suelos Ecuatoriales, v.9, p.195-201, 1978 GUPTA, U.C. Interaction effects of boron and lime of barley. Proceedings Soil Science Society of America, v.36, n.2, p.332-334, 1972.

GUPTA, U.C.; CUTCLIFFE, J.A. Effect of lime and boron on brown-heart, leaf tissue calcium boron ratios, and boron concentration of rutabaga Proceedings Soil Science Society of America, v.36, p.936-939, 1972.

HATCHER, J.T.; BOWER, C.A.; CLARK, M Adsorption of boron by soils as influenced by hydroxy aluminum and surface area. Soil Science, v.104, n.6, p.422-426, 1967.

MAROTO BORREGO, J.V. Horticultura herbácea especial. Madrid: Mundi-Prensa, 1983. 533 p.

MESQUITA FILHO, M.V.; SOUZA, A.F Constatação de deficiência nutricional de boro na cultura de cenoura. Horticultura Brasileira, Brasília, v.4, p.60, 1986

MESQUITA FILHO, M.V.; SOUZA, A.F.; SAN TOS, F.F.; OLIVEIRA, S.A. Resposta da mandioquinha-salsa à adubação com bórax em um latossolo vermelho-escuro distrófico de cerrado. Horticultura Brasileira, Brasília, v.14, n.1, p.4548, 1996.
MESQUITA FILHO, M.V.; OLIVEIRA, S.A. Influência do boro na produção de matéria seca da batata. Horticultura Brasileira, Brasília, v.2, n.2, p.9-11, 1984.

MILJKOVIC, N.S.; MATHEWS, B.S.; MILLER, M.H. The available boron content of the generic horizons of some Ontario soils. Canadian Journal of Soil Science, v.46, p.135-145, 1966.

NIELSON, G.H.; YORSTON, W. VAN LEIROF; HOST, P.B. Relationships between leaf and soil boron and boron toxicity of peaches in British Columbia. Canadian Journal Soil Science, v.65, p.213-217, 1985.

OLSON, R.V.; BERGER, K.C. Boron fixation as influenced by $\mathrm{pH}$, organic matter content and other factors. Soil Science Society of America Proceeding, v.11, p.216-220, 1946.

REISENAUER, H.M.; WALSH, L.M.; HOEFT, R.G. Testing soils for sulphur, boron, molybdenum and chlorine. In: WALSH, L.M.; BEATON, J.D. Soil testing and plant analysis. Madison: Soil Science Society of America, 1973. p.173-200.

RHOADES, J.D.; INGVALSON, R.D.; HATCHER, J.T. Laboratory determination of leachable boron. Soil Science Society of America Proceedings, v.32, p.871-876, 1970.

SIMMS, J.R.; BINGHAM, F.T. Retention of boron by layer silicates, sesquioxides and soil materials. Soil Science Society of America Proceedings, v.32, p.34-369, 1968

TRANI, P.E.; FORNASIER, J.B.; LISBÃO, R.S. Nutrição mineral de cenoura. In: FERREIRA, M.E.; CASTELLANE, P.D.; CRUZ, M.C.P. (Ed.). Nutrição e adubação de hortaliças. Piracicaba: POTAFOS, 1993. p.447-462.

USDA. Soil Conservation Service, Soil Survey Staff. Soil taxonomy: a basic system of soil classification for making and interpreting soil surveys. Washington, 1975. 754 p. (Agricultural Handbook).

VIEIRA, J.V.; RITSCHEL, P.S.; CHARCHAR, J.M.; LANA, M.M.; LIMA, D.B.; LOPES, C.A.; MOITA, A.W. Melhoramento de cenoura para regiões tropicais. BioTecnologia Ciência \& Desenvolvimento, Brasília, v.16, p.18-21, 2000.

WEAR, J.I.; PATTERSON, R.M. Effect of soil $\mathrm{pH}$ and textures on the availability of water-soluble boron in the soil. Proceedings Soil Science Society of America, v.2, n.4, p.344-346, 1962. 